\title{
PENGEMBANGAN DESA WISATA KABA-KABA DALAM PERSPEKTIF MASYARAKAT LOKAL
}

\author{
Putu Widya Darmayanti ${ }^{1}$, I Made Darma Oka ${ }^{2}$, I Wayan Sukita ${ }^{3}$ \\ 1,3 Akademi Pariwisata Denpasar, ${ }^{2}$ Politeknik Negeri Bali \\ E-mail: putuwidya4@gmail.com
}

\begin{abstract}
ABSTRAK
Artikel ini bertujuan untuk mengkaji pengembangan desa wisata Kaba-Kaba dalam persepektif masyarakat lokal. Penelitian ini menggunakan data kualitatif. Data diperoleh melalui metode observasi, wawancara, dan studi pustaka. Tokoh masyarakat yang dipergunakan sebagai informan ditentukan dengan teknik snowball sampling. Analisis data dilakukan secara deskriptif kualitatif. Hasil penelitian menunjukkan bahwa dalam perspektif masyarakat lokal, desa wisata Kaba-Kaba memiliki kekuatan dalam pengembangan kegiatan pariwisata, seperti: daya tarik wisata alam, budaya, lokasi yang strategis dengan akses yang mudah untuk dijangkau, serta memiliki fasilitas pendukung yang memadai seperti villa. Kelemahan yang dimiliki yaitu: minimnya kemampuan sumber daya manusia lokal dalam berkomunikasi bahasa asing, tenaga kerja lokal belum menguasai potensi pariwisata secara komprehensif, serta minimnya kesadaran masyarakat dalam menjaga kebersihan lingkungan. Peluangnya yaitu: adanya dukungan pelaku pariwisata, kunjungan wisatawan yang cenderung kembali ke alam, dan kini desa wisata ini menjadi lintasan baru menuju DTW Tanah Lot. Tantangan yang perlu diantisipasi yaitu: terjadi persaingan antar desa wisata sejenis, dan pencemaran lingkungan. Untuk itu pemerintah diharapkan lebih berkontribusi dalam memberikan pendidikan dan pelatihan kepada masyarakat lokal. Masyarakat diharapkan lebih bersungguh-sungguh dalam menyiapkan diri guna mampu bersaing secara kompetitif dengan desa wisata lainnya
\end{abstract}

Kata kunci: pengembangan desa wisata; persepektif masyarakat lokal;

\begin{abstract}
The aims of this article to analyze the development of Kaba-Kaba tourist village from the perspective of the local community. This research uses qualitative data. Data collection is done by observation, interview, and literature study. Informants were taken from community who understood the strengts, weaknesses, opportunities, and threats faced in development to tourist village with snowball techniques. Data were analyzed by descriptive qualitative. The results showed that Kaba-Kaba tourist village has strength in the development of tourism activities, such as: natural, cultural, tourist attractions, strategic location with easy access to reach, having supporting facilities such as villa. Weaknesses included the lack ability of local human resources to communicate the foreign languages, the employment has not undestand about tourism potential comprehensively, and the lack of public awareness in maintaining environmental cleanliness. The opportunities included supporting from tourism actors, tourist visits that trend back to nature, and the tourist village has become a new route to Tanah Lot destination. The threat to be anticipated included competition between similar tourist villages, and environmental pollution. For this reason, the government is expected to contribute in providing education and training to local communities. The community is expected to be more serious in preparing themselves to compete competitively with other tourist villages
\end{abstract}


Keywords: tourist village development; local community perspective.

\section{PENDAHULUAN}

Desa Kaba-Kaba merupakan salah satu desa wisata yang berlokasi di Kecamatan Kediri, Kabupaten Tabanan. Penetapan desa wisata ini menjadi desa wisata melalui Surat Keputusan Bupati No.180/329/03/HK\&HAM/2016. Penetapan desa ini sebagai desa wisata bertujuan untuk meningkatkan perekonomian masyarakat setempat. Kini pihak pengelola terus berbenah agar desa wisata Kaba-Kaba mampu melestarikan potensi alam dan budaya yang dimiliki sehingga mampu bersaing secara kompetitif dengan desa wisata lain sejenis. Untuk itu pihak pengelola desa wisata terus berkoordinasi, bekerjasama dan bersinergi dengan segenap stakeholder terkait demi keberlanjutan dari desa wisata.

Masyarakat lokal harus mampu berperan sebagai tuan rumah (host) dalam pengembangan desa wisata. Masyarakat menyadari bahwa keberadaan desa wisata mampu memberi peluang positif bagi masyarakat lokal baik dari segi ekonomi, sosial, maupun budaya. Oleh karena itu mereka sangat mendukung pengembangan pariwisata di desanya. Nuryanti (1993) menyebutkan bahwa pengembangan suatu desa menjadi desa wisata mengacu pada bentuk integrasi daya tarik, akomodasi dan fasilitas pendukung disajikan dalam struktur kehidupan komunitas yaitu diintegrasikan ke dalam adat dan tradisi yang berlaku agar menarik untuk dikunjungi oleh wisatawan.

Faktor sumber daya manusia memberi kontribusi besar dalam pengembangan desa wisata sehingga tanpa adanya sumber daya manusia profesional, pengelolaan desa wisata tidak berjalan dengan maksimal. Untuk itu dalam pengembangan desa wisata sebagai daya tarik wisata harus mampu mengoptimalkan pemberdayaan masyarakat (community-based tourism). Ernawati (2018); Natori (2001); dan Putra (2015) menyatakan keberhasilan pengelolaan desa wisata dapat diukur melalui penerapan pariwisata berbasis masyarakat (CBT) sehingga tercipta hubungan harmonis antara masyarakat lokal, sumber daya alam/budaya, dan wisatawan secara berkelanjutan.

Keberadaan desa wisata Kaba-Kaba tidak terlepas dari motivasi penggerak yang tinggi dalam diri masyarakat lokal. Semakin tinggi motivasi yang dimiliki masyarakat maka semakin besar pula partisipasi masyarakat dalam pengembangan desa wisata di desanya. Hal ini sejalan dengan pernyataan Meyliani, Rizky, dan Nugraha (2018) bahwa keberhasilan program desa tidak terlepas dari dorongan masyarakat untuk melibatkan diri dalam pelaksanaan kegiatan desa. Oleh karena itu motivasi masyarakat menjadi faktor kunci dalam pengembangan desa wisata. Motivasi masyarakat dalam pengelolaan desa sangat berpengaruh terhadap citra dari desa wisata. Citra yang positif tersebut merupakan modal dasar dalam mengembangkan desa Kaba-Kaba menjadi destinasi yang survival di masa depan. Baik buruknya citra secara langsung akan menentukan hidup matinya sebuah destinasi wisata. Setiap destinasi wisata senantiasa harus berusaha mengembangkan citra positif dan meminimalkan citra negatif (Hernandez-Lobato, Solis-Radilla, Moliner-Tena, \& Sanchez-Garcia, 2006; Oka \& Made, 2015; Oka \& Sumawidari, 2017; Pitana, 2002). Image yang diperoleh dari desa wisata tidak hanya mengandalkan unsur dari sumber daya manusia tetapi dilihat dari bagaimana pihak 
pengelola mampu dalam mengelola unsur kekuatan dan melihat peluang serta cara untuk meminimalkan unsur kelemahan dan tantangan yang dihadapi.

Penetapan desa Kaba-Kaba menjadi desa wisata bertujuan untuk mengembangkan keunikan desa wisata yang disajikan dalam bentuk kegiatan wisata dengan memberdayakan segenap masyarakat lokal. Pengembangan desa wisata Kaba-Kaba harus mampu mengoptimalkan unsur kekuatan yang mengandalkan unsur alam dan budaya agar desa Kaba-Kaba dapat berkelanjutan baik secara ekonomi, sosial dan budaya. Hal ini sejalan dengan penelitian Oka dan Darmayanti (2020); Oka dan Pugra (2017); Oka, Winia, dan Sadia (2018); dan Sadia dan Oka (2012) menyebutkan bahwa pengembangan pariwisata di desa wisata ditujukan untuk mengembangkan potensi lokal yang bersumber dari alam, sosial budaya guna mampu memberikan kontribusi secara ekonomi bagi kehidupan masyarakat lokal. Di sisi lain keterbatasan yang dimiliki sumber daya manusia lokal menjadi salah satu unsur kelemahan dalam pengembangan desa wisata sekaligus merupakan tantangan yang harus diantisipasi guna mampu mengembangkan desa wisata secara berkelanjutan di masa depan. Berdasarkan uraian di atas terdapat beberapa komponen yang harus diperhatikan dalam pengembangan desa wisata. Untuk itu artikel ini fokus mengkaji bagaimana kekuatan, kelemahan, peluang dan tantangan yang dihadapi dalam pengembangan desa wisata Kaba-Kaba dalam perspektif masyarakat lokal.

\section{METODE PENELITIAN}

Artikel ini menggunakan data kualitatif. Pengumpulan data melalui metode observasi, wawancara, dan studi pustaka. Data informasi tentang peluang dan tantangan dalam pengembangan desa wisata diperoleh dari tokoh masyarakat yang memahami tentang hal tersebut. Jumlah informan tidak ditentukan secara pasti. Penentuan informan dilakukan secara snowball sampling. Informan pertama diambil dari tokoh masyarakat (Kepala Desa), selanjutnya dilakukan pencarian informan lain atas petunjuk dari informan pertama, demikian seterusnya. Ketika jawaban sudah jenuh pengumpulan data dihentikan. Data dianalisis secara deskriptif kualitatif, melalui pengolahan dan penafsiran data yang merupakan rangkaian kegiatan penelahaan, pengelompokan, sistematisasi, penafsiran dan reifikasi data agar sebuah fenomena memiliki nilai sosial, akademis dan nilai ilmiah (Bungin, 2011).

\section{HASIL DAN PEMBAHASAN}

Masyarakat Kaba-Kaba masih terus berbenah dalam pengelolaan desa wisata. Para pengelola terus bekerjasama demi keberlanjutan dari pengembangan desa wisata agar mampu bersaing secara kompetitif di masa depan. Pihak desa berupaya untuk memaksimalkan potensi wisata melalui pemberdayaaan masyarakat secara optimal serta meminimalkan tantangan yang menggangu keberadaan desa wisata. Melalui komunikasi, koordinasi dan kerjasama yang harmonis diharapkan mampu menemukan solusi atas potensi yang dimiliki baik dari aspek kekuatan, kelemahan, peluang, maupun tantangan yang dihadapi dalam pengembangan desa wisata.

Pendapat para informan/tokoh masyarakat Kaba-Kaba tentang kekuatan, kelemahan, peluang, dan tantangan yang dihadapi dalam pengembangan pariwisata di masa depan, dapat diuraikan sebagai berikut: A.A Ngurah Anom (Kepala Desa 
Kaba-Kaba) dalam wawancara di Kantor Desa tanggal 15 Maret 2019, menyatakan bahwa desa wisata Kaba-Kaba memiliki kekuatan seperti: daya tarik alam berupa sawah yang dapat dijadikan sebagai aktivitas wisata trekking dan cycling. Memiliki peninggalan budaya berupa Puri Kaba-Kaba yang memiliki ciri khas tersendiri yang berbeda dengan desa wisata lainnya. Lokasi desa wisata yang strategis dekat dengan daya tarik wisata lain (Pantai Echo Beach, Pantai Petitenget) sehingga desa wisata ini mudah dijangkau oleh wisatawan. Namun disisi lain kualitas sumber daya manusia lokal perlu diberikan pembinaan dan pelatihan secara intensif agar memiliki kemampuan dalam mengelola desa wisata. Promosi juga menjadi faktor penting yang perlu dilakukan agar mampu bersaing secara kompetitif. Hal ini dilakukan agar mamp mengantisipasi tantangan yang dihadapi dengan munculnya desa wisata sejenis di sekitar desa Kaba-Kaba..

I Made Rata (Ketua Pokdarwis) dalam wawancara di Wantilan Desa tanggal 30 Maret 2019, mengungkapkan bahwa Desa Kaba-Kaba kini menjadi lintasan wisata baru sebagai penghubung antara Canggu, desa Munggu dan daya tarik wisata Tanah Lot. Desa wisata ini memiliki sawah yang menghijau merupakan ikon menarik bagi wisatawan untuk dijadikan sebagai aktivitas cycling. Untuk daya tarik budaya ada beberapa item yang menarik dikunjungi di desa ini yaitu Puri KabaKaba. Namun uniknya potensi wisata yang dimiliki tidak sebanding dengan kesadaran masyarakat dalam menjaga lingkungan sehingga perlu diberikan pemahaman tentang sadar wisata. Keterbatasan dana yang dimiliki dalam pengembangan desa wisata membuat pengelolaan desa wisata belum berjalan dengan optimal. Dukungan pelaku wisata ikut berkontribusi dalam membantu pengelolaan desa wisata. Lokasi desa yang strategis dekat dengan daya tarik wisata lain (desa Canggu, Munggu, dan Tanah Lot) mempermudah akses wisatawan untuk berkunjung ke Desa Kaba-Kaba. Kedepa masalah pencemaran lingkungan menjadi tantangan yang perlu diantisipasi dalam pengelolaan desa wisata dengan harapan mampu melestarikan lingkungan secara berkelanjutan.

Ni Made Sulatri (Pedagang Kelontong) dalam wawancara di Warungnya pada tanggal 27 Mei 2019, menyatakan bahwa desa wisata Kaba-Kaba memiliki keunikan potensi wisata yang dimiliki yaitu hamparan sawah. Lemahnya informasi yang di ketahui oleh masyarakat membuat masyarakat tidak mengetahui keunikan potensi wisata di desanya. Hal ini dikarenakan Pemda Kabupaten Tabanan minim memberikan penyuluhan kepada masyarakat tentang potensi desa. Walaupun demikian masyarakat lokal tetap termotivasi untuk menjaga lingkungan mengingat mereka menyadari betul manfaat dari menjaga lingkungan demi keberlanjutan pengembangan desa wisata. Masyarakat lokal merupakan pemeran utama sehingga pemberdayaan masyarakat lokal merupakan hal utama dalam pengembangan desa wisata. Dewi, Chafid, dan Baiquni (2013); I Made (2010); Oka dan Darmayanti (2020); Oka, Winia, dan Sadia (2019); dan Putra dan Pitana (2010) menyatakan bahwa pengembangan desa wisata dimaksudkan untuk melibatkan masyarakat lokal dalam pengembangan pariwisata sehingga mereka dan budaya mereka tidak hanya akan menjadi objek wisata tetapi mereka juga akan dibuat sadar dan terinspirasi untuk meningkatkan kesejahteraan mereka dan untuk melestarikan nilai-nilai budaya mereka melalui kegiatan wisata.

Berpedoman kepada pendapat para informan di atas, maka dapat dikemukakan kondisi eksisting dari desa wisata Kaba-Kaba, ditinjau dari kekuatan, kelemahan, peluang, dan tantangan yang dihadapi, yaitu: 


\section{Kekuatan}

a) Daya tarik wisata alam. Desa ini memiliki persawahan yang menarik untuk dikunjungi oleh wisatawan. Potensi alam ini dapat dijadikan sebagai kegiatan cycling bagi wisatawan yang ingin menikmati pemandangan sawah. Kegiatan cycling dilakukan memlui kolaborasi dengan pihak Travel Agent Bali Eco Cycling. Rutenya mulai berangkat dari Desa Kaba-Kaba, melewati jalur terasering persawahan, menyusuri pantai yang berada dekat dengan Desa Kaba-Kaba seperti pantai Canggu, Echo Beach, Tanah Lot dan Seseh, selanjutnya kembali ke tempat semula. Daya tarik wisata alam ini benar-benar dirawat oleh masyarakat demi keberlanjutan dari pengembangan desa wisata. Hal ini serupa juga trungkap dalam penelitian Utomo dan Satriawan (2017) menyatakan bahwa dalam pengembangan desa wisata yang berbasia alam (desa wisata berbasis go green) harus tetap memperhatikan keberadaan lingkungan dalam mengandalkan potensi pariwisata yang dimiliki.

b) Daya tarik wisata budaya, meliputi: Puri Kaba-Kaba. Puri ini sebagai bangunan tempat tinggal raja dan keluarganya. Ketika pengunjung memasuki Puri Kaba-Kaba, pengunjung akan disuguhi dengan arsitektur bangunan yang masih alami berupa gapura dan candi bentar. Di puri ini terdapat arca-arca tokoh berwajah asing (Arab dan Cina) sebagai bukti bahwa sejak dulu sudah terjadi akulturasi budaya lokal dengan budaya asing. Untuk menjaikan puri sebagai ikon desa wisata harus melakukan koordinasi denga baik. Hal ini terungkap dalam penelitian Wijayanti dan Sanjiwani (2019) yang menyebut bahwa untuk menjadikan puri Gede Kaba-Kaba sebagai destinasi wisata telah dilakukan melalui koordinasi dengan pihak keluarga puri.

c) Memiliki fasilitas pendukung seperti villa. Rata-rata owner villa di Desa Kaba-Kaba adalah orang asing namun mereka tetap memberdayakan masyarakat lokal sebagai karyawan dalam operasional dari villa tersebut.

\section{Kelemahan}

a) Kemampuan sumber daya manusia yang belum memadai dalam berkomunikasi bahasa asing. Minimnya kemampuan dalam komunikasi dapat mempengaruhi tingkat kepuasan tamu atas pelayanan yang diberikan, mengingat masyarakat pada umumnya kurang cakap dalam berkomunikasi dengan tamu. Hal serupa tertuang dalam penelitian Bahari dan Oka (2014) dan ; Patriani, Mataram, Oka, dan Sadia (2018) menyebutkan bahwa parameter kemampuan komunikasi dalam bahasa asing, berperan penting untuk meminimalisasi kemungkinan terjadinya miskomunikasi dalam memberikan pelayanan terhadap wisatawan.

b) Masyarakat belum menguasai secara komprehensif tentang potensi pariwisata yang dimiliki. Rendahnya pemahaman potensi wisata tersebut menyulitkan mereka dalam menginformasikan secara detail untuk dapat menjadi atraksi wisata yang menarik bagi wisatawan. Potensi yang biasa saja, apabila disampikan oleh seorang yang bertalenta, hal yang biasa tersebut akan dikemas secara apik sehingga menjelma menjadi sebuah atraksi atau paket wisata yang atraktif.

c) Masih minim kesadaran masyarakat dalam menjaga lingkungan. Masyarakat merupakan sekelompok seseorang yang tinggal dalam satu wilayah yang memiliki karakteristik yang berbeda-beda. Pada proses mengembangkan desa wisata, pelibatan masyarakat menjadi prasyarat mutlak. Kesadaran 
masyarakat masih rendah terkait dengan kebersihan lingkungan masih perlu diberikan motivasi baik berupa penyuluhan maupun pelatihan terkait pariwisata.

3. Peluang yang dimiliki, yaitu:

a) Dukungan pelaku wisata dalam pengembangan desa wisata. Para pelaku wisata khususnya "Bali Eco Cycling" telah berpartisipasi aktif dalam penyediaan sepeda dalam mendukung kegiatan cycling di desa. Hal ini perlu ditumbuhkan kembali guna mampu menarik partisipasi dari pelaku pariwisata lainnya.

b) Kunjungan wisatawan untuk kembali ke alam (back to nature) menjadi tren karena kecenderungan wisatawan untuk berwisata edukasi tentang alam di sekitarnya dan budaya yang dimiliki oleh masyarakat yang disajikan dalam bentuk kegiatan wisata. Tren back to nature menjadikan desa wisata sebagai salah satu bentuk wisata yang sangat potensial dimana kegiatan wisata tersebut mampu menciptakan pengalaman berkualitas bagi wisatawan yang berkunjung ke desa wisata. Pertumbuhan jumlah kunjungan wisatawan ke daya tarik wisata (DTW) di Kabupaten Tabanan dalam lima (5) tahun terakhir mengalami pertumbuhan rata-rata sebesar $4,64 \%$. Hal ini memberi peluang yang signifikan terhadap kunjungan wisatawan ke desa wisata mengingat bahwa pengelolaan desa wisata memanfaatkan unsur kealamian seperti alam dan budaya.

c) Desa wisata Kaba-Kaba menjadi lintasan baru karena aksesnya dekat dengan daerah Munggu dan Canggu. Hal ini menjadikan desa wisata Kaba-Kaba memiliki lokasi strategis karena dekat dengan daya tarik wisata lain, seperti: Pantai Echo Beach, Petitenget dan DTW Tanah Lot.

4. Tantangan yang perlu untuk diantisipasi, yaitu:

a. Terjadinya persaingan dengan desa wisata sejenis. Munculnya desa wisata baru juga menjadi tantangan bagi pengembangan desa Kaba-kaba karena hampir sebagian besar menawarkan objek wisata sejenis. Untuk itu pihak pengelola harus lebih konsentrasi dalam menggali potensi wisata yang dimiliki demi mampu menawarkan ciri khas yang berbeda.

b. Terjadinya pencemaran lingkungan. Kondisi ini di masa depan harus segera diantisipasi mulai dari sekarang. Hal ini diantisipasi oleh pihak pengelola dengan mengadakan kegiatan kebersihan lingkungan dimana melibatkan masyarakat secara massif sekaligus memberikan penyuluhan tentang manfaat positif dari keterlibatan masyarakat dalam menjaga kebersihan lingkungan.

Berpedoman pada uraian di atas, dalam pengembangan desa wisata KabaKaba harus dilakukan dengan menerapkan konsep "sustainable tourism" agar pengembangan pariwisata di desa ini dapat berkelanjutan. Pongsakornrungsilp (2014) mengemukakan bahwa terdapat empat komponen penting untuk pariwisata berkelanjutan. Pertama, harus ada potensi wisata yang tinggi di berbagai bidang seperti sumber daya alam yang melimpah untuk menunjang berbagai kegiatan, dan ketersediaan pemandu lokal yang dapat mendukung pariwisata melalui transfer ilmu dan pemahaman kepada masyarakat. Kedua, pola pikir berkelanjutan. Harus ada berbagi sumber daya dan berbagi pengetahuan di antara anggota komunitas untuk menciptakan pemahaman di antara anggota. Ketiga, jaringan pariwisata. Jaringan dan integrasi pariwisata akan membantu mengurangi konflik antar 
masyarakat dan menghindari masalah persaingan bagi wisatawan. Komponen keempat adalah kepemimpinan; harus ada pemimpin kelompok masyarakat yang kuat, mampu menumbuhkan pemahaman bagi anggota dan masyarakat, serta dapat berkoordinasi untuk mendapatkan dukungan dari lembaga eksternal.

Dalam pengembangan desa wisata berkelanjutan, dalam pengelolaanya harus melibatkan masyarakat lokal (pariwisata berbasis masyarakat). Hal ini bertujuan untuk meningkatkan kesadaran masyarakat dalam melestarikan alam dan budaya yang dimiliki. Disadari pula bahwa dalam pengembangan pariwisata berbasis masyarakat biasanya membutuhkan fasilitasi dan bantuan eksternal, untuk itu disarankan untuk dapat menjalin kemitraan dengan entitas eksternal. Berbagai model polal kemitraan dimungkinkan, tetapi juga ada argumen untuk meminimalisasi keterlibatan eksternal dalam pengelolaan pariwisata (Dodds, Ali, \& Galaski, 2016). Diharapkan bahwa dalam pengelolaan pariwisata sepenuhnya dikendalikan, dimiliki, dan dikelola oleh anggota masyarakat yang kurang beruntung (terpinggirkan). Berbagai entitas dapat terlibat dalam kemitraan dengan pihak pengelola seperti sektor swasta, LSM, dan entitas pemerintah (Mtapuri \& Giampiccoli, 2016). Mereka diharapkan dapat memainkan peran berbeda dalam pengembangan pariwisata berbasis masyarakat (Giampiccoli, Saayman, \& Jugmohan, 2014). Namun demikian, peran pemerintah tetap dianggap fundamental dalam pengembangan pariwisata berbasis masyarakat (Connelly \& Sam, 2018). Pemerintah harus menjadi protagonis utama, yang tugasnya adalah untuk "merumuskan definisi resmi dari bentuk pariwisata untuk menginformasikan peraturan dan kebijakan kepada masyarakat.

\section{SIMPULAN}

Pengembangan desa Kaba-Kaba menjadi desa wisata karena memiliki unsur-unsur sumber daya pariwisata yang memadai, seperti: sumber daya alam, sumber daya budaya, sumber daya manusia, serta aksesibilitas yang diukur dari aspek kekuatan, kelemahan, peluang dan tantangan yang dihadapi. Dalam persepektif masyarakat lokal, desa Kaba-Kaba memiliki berbagai potensi wisata yang menjadi sumber kekuatan dalam pengembangan kegiatan desa wisata, seperti: daya tarik wisata alam, budaya, lokasi yang strategis dengan akses yang mudah untuk dijangkau, serta memiliki fasilitas pendukung yang memadai seperti villa. Kelemahan yang dimiliki yaitu: minimnya kemampuan sumber daya manusia lokal dalam berkomunikasi bahasa asing, belum menguasai potensi pariwisata secara komprehensif, minimnya kesadaran masyarakat dalam menjaga kebersihan lingkungan. Peluangnya yaitu: adanya dukungan pelaku pariwisata, kunjungan wisatawan yang cenderung kembali ke alam, dan kini desa wsiata ini menjadi lintasan baru menuju DTW Tanah Lot. Tantangan yang perlu diantisipasi yaitu: terjadi persaingan antar desa wisata sejenis, dan pencemaran lingkungan. Untuk itu pemerintah diharapkan berkontribusi lebih dalam memberikan pendidikan dan pelatihan kepada masyarakat lokal. Selain itu masyarakat lokal diharapkan lebih bersungguh-sungguh dalam menyiapkan diri guna mampu mengelola desa wisata secara berkelanjutan sehingga dapat bersaing secara kompetitif dengan desa wisata sejenis. 


\section{DAFTAR PUSTAKA}

Bahari, N. M. Y., \& Oka, I. M. D. (2014). Persepsi Wisatawan Mancanegara terhadap Pelayanan Butler di Akara Villas Kuta. Jurnal Ilmiah Hospitality Management, 5(1), 47-56.

Bungin, B. (2011). Metode Penelitian Kualitatif Aktualisasi Metodologis ke Arah Ragam Varian Kontemporer. Jakarta: PT Raja Grafindo Persada.

Connelly, A., \& Sam, S. (2018). How can policy assist the development of community-based tourism in Guyana by 2025 and beyond? Worldwide Hospitality and Tourism Themes, 10(5), 555-568.

Dewi, M. H. U., Chafid, F., \& Baiquni, M. (2013). Pengembangan Desa Wisata Berbasis Partisipasi Masyarakat Lokal Di Desa Wisata Jatiluwih, Tabanan. Bali. Jurnal Kawistara, 3(2), 117-226.

Dodds, R., Ali, A., \& Galaski, K. (2016). Mobilizing Knowledge: Determining Key Elements for Success And Pitfalls in Developing Community-Based Tourism. Current Issues in Tourism, 21(13), 1547-1568. https://doi.org/10.1080/13683500.2016.1150257

Ernawati, N. . (2018). Pariwisata Berbasis Masyarakat. Denpasar: Swasta Nulus.

Giampiccoli, A., Saayman, M., \& Jugmohan, S. (2014). Developing CommunityBased Tourism In South Africa: Addressing The Missing Link. African Journal for Physical, Health Education, Recreation and Dance, 20(3-2), $1139-1161$.

Hernandez-Lobato, L., Solis-Radilla, M. M., Moliner-Tena, M. A., \& SanchezGarcia, J. (2006). Tourism Destination Image, Satisfation and Loyalty; A case study in Ixtapa-Zihuatanejo. Mexico: Tourism Geographiec, 8(4), 343-358.

I Made, D. O. (2010). Reclamation the Beach of Sanur: Economic and Sociacultural Perspective of the Balinese Community. Mudra (Jurnal Seni Budaya), 25(2), 1-1.

Meyliani, L., Rizky, L., \& Nugraha. (2018). Keinginan untuk maju: Strategi Desa Ranuklindungan dalam Mewujudkan Desa Wisata. Kepariwisataan Dan Hospitalitas, 2(2), 63-76.

Mtapuri, O., \& Giampiccoli, A. (2016). Towards A Comprehensive Model Of Community-Based Tourism Development. South African Geographical Journal, 98(1), 154-168.

Natori, M. (2001). A guidebook for Tourism Based Community- Development. Japan: Aptec.

Nuryanti, W. (1993). Concept, Perspective, and Challenges. Laporan Konferensi International Mengenai Pariwisata Budaya, 2-3.

Oka, I. M. D., \& Darmayanti, P. W. (2020). Environmental Factors: Dominant Motivation of the Bongan Community to Support the Development of Tourist Village. Journal of Business on Hospitality and Tourism, 6(1), 104-112.

Oka, I. M. D., \& Made, I. (2015). Perempuan Bali Dalam Industri Pariwisata Kapal Pesiar. Universitas Udayana.

Oka, I. M. D., \& Pugra, I. W. (2017). The Impacts of Balinese Women Working in Cruise Ship. International Journal of Applied Sciences in Tourism and Events, $1(1), 51$.

Oka, I. M. D., \& Sumawidari, I. A. K. (2017). Image Daya Tarik Wisata Alas Kedaton di Desa Kukuh, Marga, Tabanan. Soshum: Jurnal Sosial Dan 
Humaniora, 3(2), 202.

Oka, I. M. D., Winia, I. N., \& Sadia, I. K. (2018). Pemetaan Potensi Pariwisata Dalam Mendukung Pengembangan Pariwisata Di Desa Serangan. Bhakti Persada Jurnal Aplikasi IPTEKS, 4(1), 47-54.

Oka, I. M. D., Winia, I. N., \& Sadia, I. K. (2019). The Implication of the Development of Serangan Tourist Village from the Economic Perspective. International Conference on Social Science 2019 (ICSS 2019). Atlantis Press.

Patriani, N. K. T., Mataram, I. G. A. B., Oka, I. M. D., \& Sadia, I. K. (2018). Analysis of Receptionist Service Quality for the Tourists 'satisfaction at The Grand Inna Hotel Kuta. Journal of Applied Sciences in Travel and Hospitality, $1(3), 228$.

Pitana, I. G. (2002). Apresiasi Kritis Terhadap Kepariwisataan. Denpasar: Print Works.

Pongsakornrungsilp, P. (2014). The Management Of Sustainable CommunityBased Tourism: The Case Of Ban Kokekrai, Phangnga Province. Veridian EJournal, 7(3), 650-665.

Putra, I. N. D. (2015). Pariwisata Berbasis Masyarakat Model Bali. Denpasar: Universitas Udayana.

Putra, I. N. D., \& Pitana, I. G. (2010). Pariwisata Pro-Rakyat Meretas Jalan Mengentaskan Kemiskinan di Indonesia. Jakarta: Kementerian Kebudayaan dan Pariwisata.

Sadia, I. K., \& Oka, I. M. D. (2012). Motivasi Tenaga Kerja Bali Bekerja di Mediterranean Shipping Company (MSC). Jurnal Sosial Humaniora, 2(3), 221-236.

Utomo, S. J., \& Satriawan, B. (2017). Strategi Pengembangan Desa Wisata Di Kecamatan Karangploso Kabupaten Malang. Neobis, 11(2), 142-153.

Wijayanti, I. G. A. K. M., \& Sanjiwani, P. K. (2019). Pengelolaan Desa Wisata Kaba-Kaba, Kecamatan Kediri, Kabupaten Tabanan: Suatu Analisisi Kualitatif. Jurnal Destinasi Pariwisata, 7(2), 344-351. 